\title{
Toxic effects of various zinc dosages on poultry hemopoiesis
}

\author{
Aleksandr Vishnyakov ${ }^{1, *}$ \\ ${ }^{1}$ Orenburg state university, 1, 3, prospekt Pobedy, 460018, Orenburg, Russia
}

\begin{abstract}
The aim of the study was to determine the main patterns of the manifestation of the toxic effect of zinc chloride on the cells of the red bone marrow in the first three days after exposure. Our experiment involved broiler chickens of the "Smena-7" cross. The work presents new data on the effects of zinc salts in doses of $40 \mathrm{mg} / \mathrm{kg}$ and $60 \mathrm{mg} / \mathrm{kg}$ on the hemopoietic cells of the red bone marrow of birds at the ultrastructural level. Thus, the results of the study showed zinc poisoning of chickens even within 1-3 days led to damage to bone marrow cells. The cytoplasm of blood-forming and stromal cells of the bone marrow detects mostly signs of destructive processes, which are amplified as the duration and the dose of exposure increase. At the same time, the structure of cell nuclei often gets changed in the bone marrow. Emerging morphological signs indicate a decrease in the transcription of ribosomal RNA genes of bone marrow cells. In the bone marrow, the number of basophil erythrokaryocytes increases and the number of hemoglobinized forms of red blood cells decreases. Zinc mainly causes disorders of morphofunctional structures in erythroblasts and mature cells of other bone marrow cell lines.
\end{abstract}

\section{Introduction}

The intensive development of industry in recent years has made the problem of pollution and the survival of mankind in these conditions a central problem of our time and has affected all areas of human activity. In some cases, the technological processes went out of control resulting in a rapid accumulation of non-biosphere substances (radionuclides, heavy metals, and other toxicants) [1].

Among the major environmental pollutants, there are heavy metals and xenobiotics, which excessive entering trophic chains is dangerous for the health of animals and humans [2].

According to several authors, ions of such heavy metals as zinc, cadmium, lead, mercury, chromium, copper, nickel, molybdenum, and others with increased content in the environment can inhibit the vitality of many living organisms and induce a non-enzyme cleavage of chemical bonds in DNA molecules leading to single- and bi-string cleavages with the formation of chromosomal aberrations, which influences the synthesis of DNA in the cell and causes the genome repression [3-5].

\footnotetext{
*Corresponding author : kwan111@yandex.ru
} 
The aim of the study was to determine the main patterns of the manifestation of the toxic effect of zinc chloride on the cells of the red bone marrow in the first three days after exposure.

\section{Materials and methods}

Our experiment involved broiler chickens of the "Smena-7" cross. They intraperitoneally received zinc chloride in doses of $40 \mathrm{mg} / \mathrm{kg}$ and $60 \mathrm{mg} / \mathrm{kg}$ for one time. Materials for electron-microscopic examination were taken on the first day and in three days. For the ultrafine study, the bone marrow was fixated in a $2.5 \%$ solution of glutaraldehyde on a phosphate buffer followed by an hour-long fixation with $1 \%$ OsO4 solution on the same buffer. After processing with a saturated solution of uranyl acetate on $70 \%$ ethanol, the material was dehydrated in the alcohols of ascending proof and encased in epon. Ultra-thin sections were studied at the translucent electron microscope JEM - 100 CX II (JEOL, Japan).

One day after zinc intoxication, there were registered signs of marked structural changes in many bone marrow cells even at a dose of $40 \mathrm{mg} / \mathrm{kg}$. The stromal reticular cells of the bone marrow were subject to dystrophic changes. The cytoplasm was characterized by single swollen mitochondria with decaying cristae, finely vacuolated mitochondrial matrix, various vesicles, and bubbles. The chromatin in the nuclei partially collapsed, although the shape of the nuclei did not change remaining rounded or a bit elongated.

\section{Results and discussion}

Macrophages of the bone marrow had heterogeneous cytoplasm with a lot of different electron-density large and small rounded inclusions, numerous bubbles. Most organelles in the cytoplasm of the macrophages were not visible. Perinuclear spaces in the cells were a bit expanded. Heterochromatin in the nuclei of the macrophages degraded, it was defined in the form of rounded and vague dark islets in karyoplasm (Figure 1).

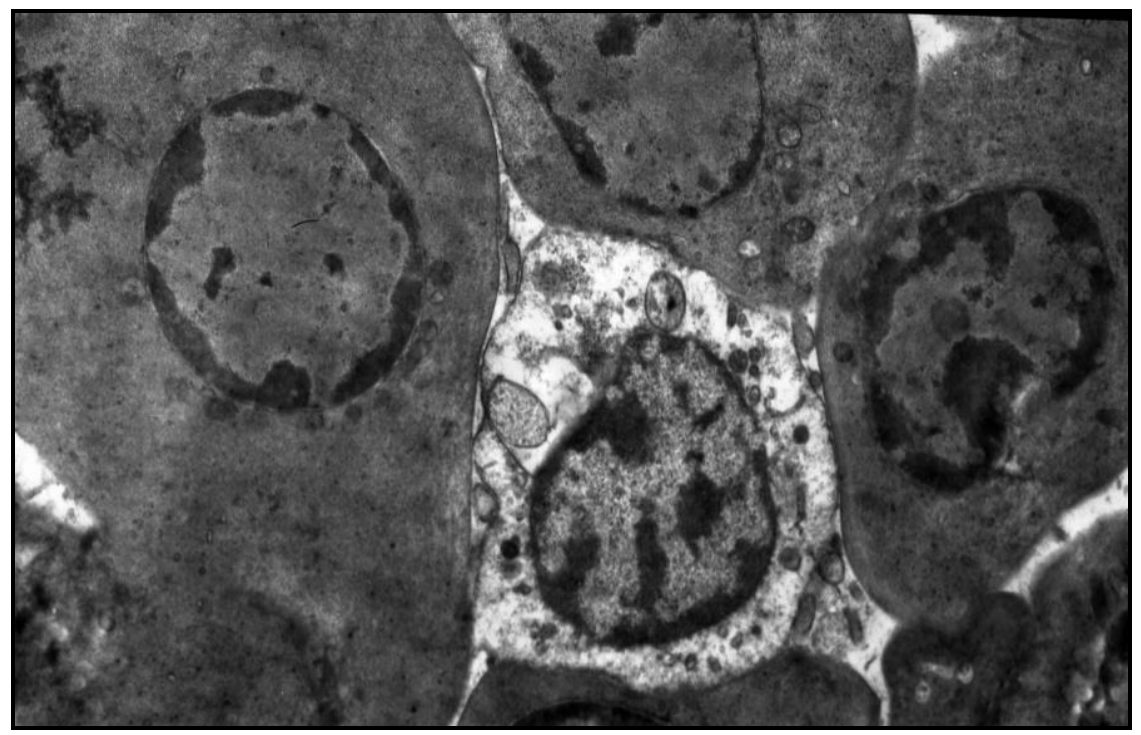

Fig. 1. The destruction of ribosomes and polyribosomes, mitochondria, homogenization of the cytoplasm of erythroblasts and erythrokaryocytes in the bone marrow of chickens 1 day after zinc intoxication at a dose of $40 \mathrm{mg} / \mathrm{kg}$. Electron diffraction pattern. $x 7200$. 
Erythroblasts and erythrokaryocytes of erythroblastic islets surrounding these macrophages were also characterized by morphological changes (Figure 2). Ribosomes and polyribosomes, single mitochondria were subjected to the destruction, the cytoplasm often got homogenized.

Some cells had perinuclear spaces expanded. The cells either were of an elongated form or had a variety of shapes instead of a normally rounded shape.

There was determined heterochromatin in a large amount in many nuclei of erythroblastic cells (mostly on the periphery). The heterochromatin was strongly compacted on the inside of the karyolemma. Some red blood cells had nuclei reduced in size, compacted, and exposed to karyopyknosis (Figure 3). The bone marrow showed an increase in the number of basophil erythrokaryocytes, non-nuclear reticulocytes and a decrease in hemoglobinized forms of red blood cells.

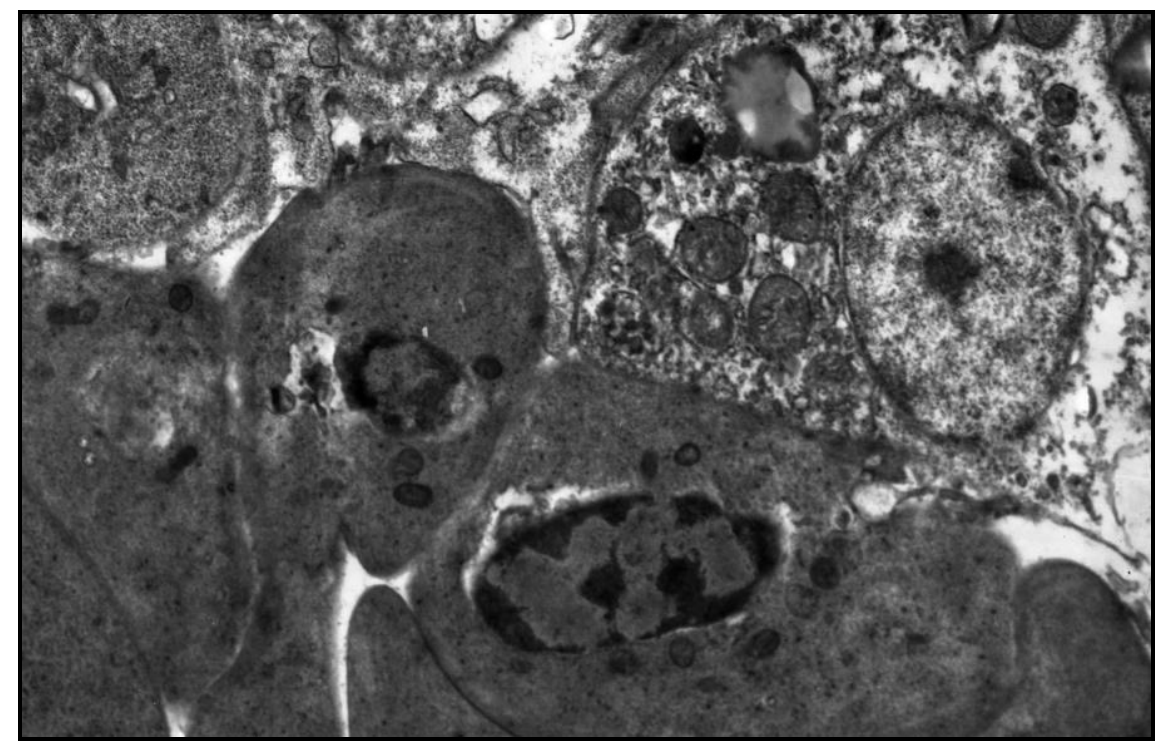

Fig. 2. Karyopyknosis red blood cell's nucleus in the bone marrow of chickens 1 day after zinc intoxication at a dose of $40 \mathrm{mg} / \mathrm{kg}$. Electron diffraction pattern. x7200.

Three days after the zinc intoxication of chickens at a dose of $40 \mathrm{mg}$ per $\mathrm{kg}$, destructive processes in bone marrow cells increased. Dystrophic changes were present in both hemopoietic cells and bone marrow stromal cells. The least pronounced cell changes were manifested in the partial destruction of cristae in the mitochondria, the relatively weak expansion of the SER channels, and the vacuolization of cytoplasm. Also, cells sometimes formed various protrusions of the cytoplasm. The most pronounced morphological changes of cells included the complete destruction of organelles, the formation of heterogeneous lipid inclusions instead of the organelles, the expressed vacuolization of cytoplasm, and the strong expansion of perinuclear space. These changes were more related to mature forms of blood-forming cells. 


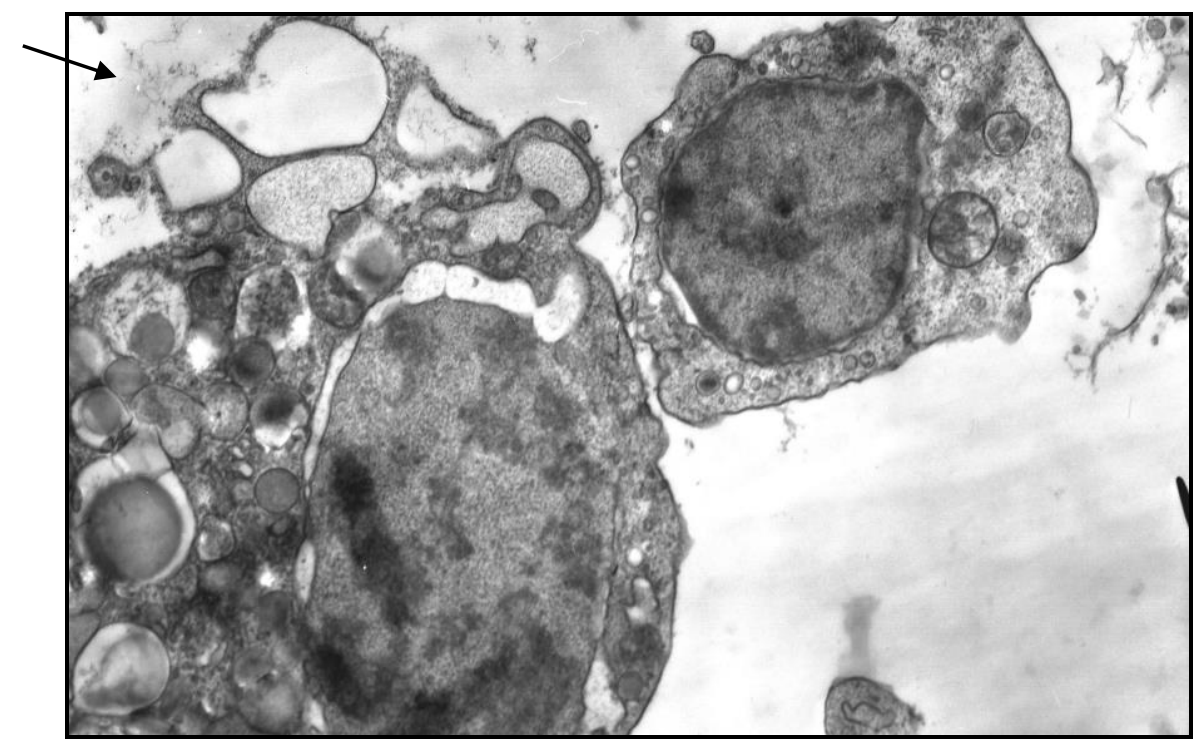

Fig. 3. The destruction of organelles, vacuolization of cytoplasm, the destruction of chromatin in the nucleus of the chicken bone marrow cell 3 days after zinc intoxication at a dose of $40 \mathrm{mg} / \mathrm{kg}$. Electron diffraction pattern. $x 7200$.

Cells of the erythroid range were the most recognizable. Mitotic figures were not determined. There sometimes were blast young cells with almost completely remained structure.

It should be noted that pathological changes in most cells related to nuclear material.

With the increased concentration of zinc $(60 \mathrm{mg} / \mathrm{kg})$, dystrophic changes in bone marrow cells after the first day were almost the same as in the group of chickens intoxicated with a dose of $40 \mathrm{mg}$ after day 1.

Three days after the zinc intoxication with the dose of $60 \mathrm{mg} / \mathrm{kg}$ revealed that destructive changes in blood-forming and stromal cells of the bone marrow increased. Organelles were often completely destroyed or vacuolated, and they were replaced by heterogeneous inclusions or vacuoles in the cytoplasm.

After three days of the zinc intoxication, most bone marrow cells were characterized with changes in the structure of the nucleus regardless of which line a cell belongs to. They were of different nature: it sometimes manifested in the condensation of chromatin in the nucleus; sometimes, on the contrary, in the destruction of chromatin and bleaching of the nucleus, the separation of the filamentary component of the nucleus, and the destruction of the nuclei. Cells often experienced karyopyknosis - the shrinkage of the nucleus (Figure 4). 


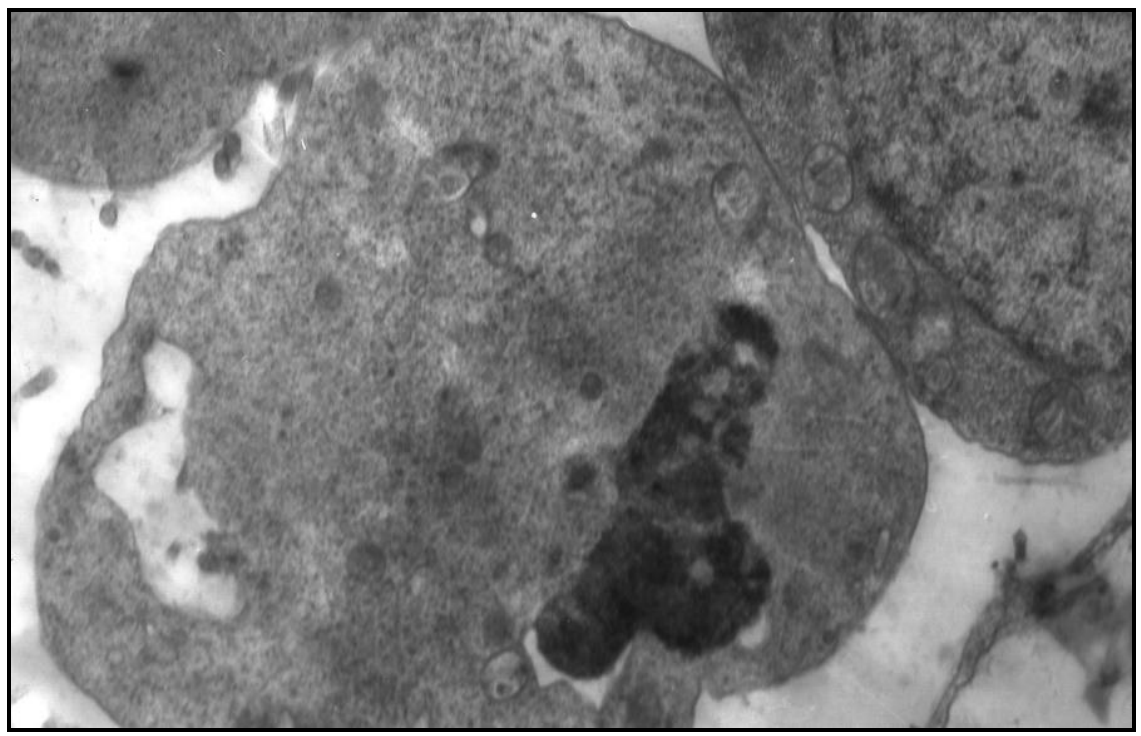

Fig. 4. Karyopyknosis in a bone marrow cell of a chicken 3 days after the zinc intoxication at a dose of $60 \mathrm{mg}$ per $\mathrm{kg}$. Electron diffraction pattern. x10000.

\section{Conclusion}

Thus, the results of the study showed zinc poisoning of chickens even within 1-3 days led to damage to bone marrow cells. The cytoplasm of blood-forming and stromal cells of the bone marrow detects mostly signs of destructive processes, which are amplified as the duration and the dose of exposure increase [7]. At the same time, the structure of cell nuclei often gets changed in the bone marrow. Emerging morphological signs indicate a decrease in the transcription of ribosomal RNA genes of bone marrow cells. In the bone marrow, the number of basophil erythrokaryocytes increases and the number of hemoglobinized forms of red blood cells decreases. Zinc mainly causes disorders of morpho-functional structures in erythroblasts and mature cells of other bone marrow cell lines [8-9]. Increasing the dose of zinc chloride stated deeper changes in the red bone marrow of birds.

\section{References}

1. L. Plum, L. Rink, H. Hajo, International Journal of Environmental Research and Public Health 7(4), 1342-1365 (2010) DOI: 10.3390/ijerph7041342

2. B. Semete, L. Boysen, Y. Lemmer, Nanomedicine: Nanotechnology, Biology, and Medicine 6(5), 662-671 (2010) DOI: 10.1016/j.nano.2010.02.002

3. Y. Chang, M. Zhang, L. Xia, Materials 5(12), 2850-2871 (2012) DOI: $10.3390 / \mathrm{ma} 5122850$

4. M. Jaishankar, T. Tseten, N. Anbalagan, Interdisciplinary Toxicology 7(2), 60-72 (2014) DOI: 10.2478/intox-2014-0009

5. I. Alkorta, J. Hernández-Allica, J. Becerril, Reviews in Environmental Science and Biotechnology 3(1), 71-90 (2004) DOI: 10.1023/B:RESB.0000040059.70899.3d

6. A. Vishnyakov, D. Udavliev, D. Timofeev, IOP Conference Series: Earth and Environmental Science 341(1) (2019) DOI: 10.1088/1755-1315/341/1/012041 
7. V. Stybel, B. Gutyj, I. Hariv, Scientific Messenger of LNU of Veterinary Medicine and Biotechnologies 21(94), 157-162 (2019) DOI: 10.32718/nvlvet9429

8. S. Park, S. Birkhold, L. Kubena, Biological Trace Element Research 101(2), 147-163 (2004) DOI: 10.1385/BTER:101:2:147

9. K. Sahin, N. Sahin, O. Kucuk, Poultry Science 88(10), 2176-83 (2009) DOI: $10.3382 /$ ps.2008-00560

10. S. Naz, M. Idris, M. Khalique, World's Poultry Science Journal 1, 1-10 (2016). DOI: $10.1017 / \mathrm{S} 0043933915002755$

11. L. Star, J. van der Klis, C. Rapp, Poultry Science 91(12), 3115-3120 (2012) DOI: $10.3382 /$ ps.2012-02314 